\title{
Hydrothermal synthesis of perovskite and pyrochlore powders of potassium tantalate
}

\author{
Gregory K.L. Goh ${ }^{\text {a) }}$ \\ Materials Department and Materials Research Laboratory, University of California-Santa Barbara, \\ Santa Barbara, California 93106 \\ Sossina M. Haile \\ Materials Science Department 138-78, California Institute of Technology, 1200 California Boulevard, \\ Pasadena, California 91125 \\ Carlos G. Levi and Fred F. Lange \\ Materials Department and Materials Research Laboratory, University of California-Santa Barbara, \\ Santa Barbara, California 93106
}

(Received 16 May 2002; accepted 17 September 2002)

Potassium tantalate powders were hydrothermally synthesized at 100 to $200{ }^{\circ} \mathrm{C}$ in 4 to $15 \mathrm{M}$ aqueous $\mathrm{KOH}$ solutions. A defect pyrochlore, $\mathrm{KTa}_{2} \mathrm{O}_{5}(\mathrm{OH}) \cdot n \mathrm{H}_{2} \mathrm{O}(n \approx 1.4)$, was obtained at $4 \mathrm{M} \mathrm{KOH}$, but at 7-12 $\mathrm{M} \mathrm{KOH}$, this pyrochlore was gradually replaced by a defect perovskite as the stable phase. At $15 \mathrm{M} \mathrm{KOH}$, there was no intermediate pyrochlore, only a defect perovskite, $\mathrm{K}_{0.85} \mathrm{Ta}_{0.92} \mathrm{O}_{2.43}(\mathrm{OH})_{0.57} \cdot 0.15 \mathrm{H}_{2} \mathrm{O}$. Synthesis at higher $\mathrm{KOH}$ concentrations led to greater incorporation of protons in the perovskite structures. The potassium vacancies required for charge compensation of incorporated protons could accommodate water molecules in the perovskite structure.

\section{INTRODUCTION}

The perovskite $\mathrm{KTaO}_{3}$ is an incipient ferroelectric that exhibits a dielectric nonlinearity at low temperatures, on the order of the transition temperature of high- $\mathrm{T}_{\mathrm{c}}$ superconductors. As such, a potential application is as a tunable element in microwave circuits. ${ }^{1}$ In addition, its close lattice match with the ferroelectric $\mathrm{KNbO}_{3}$ system makes it an ideal buffer layer for the growth of $\mathrm{KNbO}_{3}$ films. ${ }^{2}$ The growth of $\mathrm{KTaO}_{3}$ films by the hydrothermal method was carried out and detailed in a separate study. ${ }^{3}$ To gain a better understanding of the growth processes, potassium tantalate powders that precipitated along with the films were examined. Details of the defect and structural chemistries of these powders are the subject of the present study.

Traditionally, hydrothermal synthesis is used to produce inorganic phases at moderate temperatures ( $\mathrm{T}=400$ to $700{ }^{\circ} \mathrm{C}$ ) and very high pressures. Recently, it has been used for low-temperature $\left(\leqslant 200{ }^{\circ} \mathrm{C}\right)$ synthesis of powders and films of several oxides, including $\mathrm{BaTiO}_{3}$ and $\mathrm{Pb}(\mathrm{Zr}, \mathrm{Ti}) \mathrm{O}_{3}{ }^{4,5}$ In contrast, current

\footnotetext{
a) Address all correspondence to this author. Present address: Institute of Materials Research and Engineering, 3 Research Link, Singapore 117602, Republic of Singapore e-mail: g-goh@imre.org.sg
}

techniques for synthesizing $\mathrm{KTaO}_{3}$ powders require relatively high temperatures. Conventional solid-state synthesis based on mixed powders requires long periods of heating at $1000{ }^{\circ} \mathrm{C} .{ }^{6}$ Alternatively, when using precursors such as alkoxides, a defect pyrochlore phase, $\mathrm{K}_{2} \mathrm{Ta}_{2} \mathrm{O}_{6}$ crystallizes at $650{ }^{\circ} \mathrm{C}$; the perovskite phase is obtained only after heating to $850{ }^{\circ} \mathrm{C} .{ }^{7}$ Attempts to generate potassium tantalate powders by the hydrothermal method have, to date, produced materials with only a defect pyrochlore structure. ${ }^{8}$ This paper details the first report of the hydrothermal synthesis of $\mathrm{KTaO}_{3}$ powders with the perovskite structure at temperatures of $200{ }^{\circ} \mathrm{C}$ and lower.

\section{EXPERIMENTAL}

A series of powders was synthesized by reacting $0.0025 \mathrm{~mol} \mathrm{Ta}_{2} \mathrm{O}_{5}$ powder in $25 \mathrm{ml}$ aqueous, alkaline solutions containing 4 to $15 \mathrm{M} \mathrm{KOH}$ at 100 to $200{ }^{\circ} \mathrm{C}$ in a $45 \mathrm{ml}$ Teflon-lined, stainless steel hydrothermal container (Parr Co., Moline, IL). After the reaction, the powders were filter-washed with deionized water and dried at $100{ }^{\circ} \mathrm{C}$

The morphology of the powders was examined with field emission scanning electron microscopy (SEM; 6300F, JEOL Ltd., Tokyo, Japan). Compositional analysis was performed by energy-dispersive spectroscopy 
(EDS; Oxford Instruments, Oxford, United Kingdom). Phases were identified by x-ray diffraction (XRD; Philips X'pert and Philips Materials Research Diffractometer, Philips, Mahwah, NJ). The lattice parameters of the powders were determined based on peak positions for the $\mathrm{K}_{2} \mathrm{Ta}_{2} \mathrm{O}_{6}(800)$ and $\mathrm{KTaO}_{3}(400)$ phases reported in the literature,,${ }^{9,10}$ using the silicon (400) and (511) peaks respectively, as external standards. In situ XRD measurements were performed in vacuum $\left(3 \times 10^{-4}\right.$ torr $)$ from room temperature to $320{ }^{\circ} \mathrm{C}$ using a hot stage with the Philips X'pert diffractometer.

The presence of protons in the powders was determined by ${ }^{1} \mathrm{H}$ magic-angle spinning nuclear magnetic resonance (MAS NMR, $12 \mathrm{kHz}$ spinning rate) on a DSX 500 spectrometer (Bruker, Germany) at room temperature $\left(25^{\circ} \mathrm{C}\right)$ with an external tetra-methyl-silane reference. The presence of water in the powders was determined by Fourier transformed infrared (FTIR) spectroscopy (Magna IR 850 Series II, Nicolet, Madison, WI). For FTIR, powders were diluted to about $1 \mathrm{wt} \%$ within $\mathrm{KBr}$, and this mixture was heated at $130{ }^{\circ} \mathrm{C}$ in a vacuum oven for at least $4 \mathrm{~h}$ to remove excess surface water before analysis in dry nitrogen at room temperature. Each spectrum collected $\left(400-4000 \mathrm{~cm}^{-1}\right)$ was the average of 64 measurements at $4 \mathrm{~cm}^{-1}$ resolution. Thermogravimetric analyses (TGA/sDTA 851e, Mettler, Toledo, $\mathrm{OH}$ ) coupled with mass spectrometry; ThermoStar, Pfeiffer Vacuum, Nashua, NH) were carried out to quantify the water content of the powders. The cycle involved heating about $30 \mathrm{mg}$ of powder at $10{ }^{\circ} \mathrm{C} / \mathrm{min}$ to $900{ }^{\circ} \mathrm{C}$ in a dry nitrogen atmosphere.

\section{RESULTS}

\section{A. General observations}

The XRD spectra in Fig. 1 show that synthesis at $200{ }^{\circ} \mathrm{C}$ in $7 \mathrm{M} \mathrm{KOH}$ yields a pyrochlore as an intermediate product prior to the evolution of a perovskite phase. The pyrochlore powder synthesized after $2 \mathrm{~h}$ had a lattice parameter of $10.623 \AA$, significantly larger than the value of $10.5961 \AA$ for $\mathrm{K}_{2} \mathrm{Ta}_{2} \mathrm{O}_{6}$ reported in the literature. ${ }^{9}$ The perovskite structure obtained from the same solution after $24 \mathrm{~h}$ was cubic and had a lattice parameter of $3.991 \AA$, which agrees quite well with the literature value of $3.989 \AA$ for $\mathrm{KTaO}_{3}{ }^{10}{ }^{10}$ As shown in Fig. 2, the pyrochlore and perovskite particles exhibited distinctly different morphologies-octahedral and cubic, respectively. The $\mathrm{K} / \mathrm{Ta}$ ratios of the pyrochlore and perovskite phases, determined by EDS were 0.51 and 0.93 , respectively, both less than their expected stoichiometry of 1.0.

Table I shows the different phases present in the powders synthesized at different temperatures and $\mathrm{KOH}$ concentrations; the perovskite was the only phase observed at higher temperatures and higher $\mathrm{KOH}$ concentrations

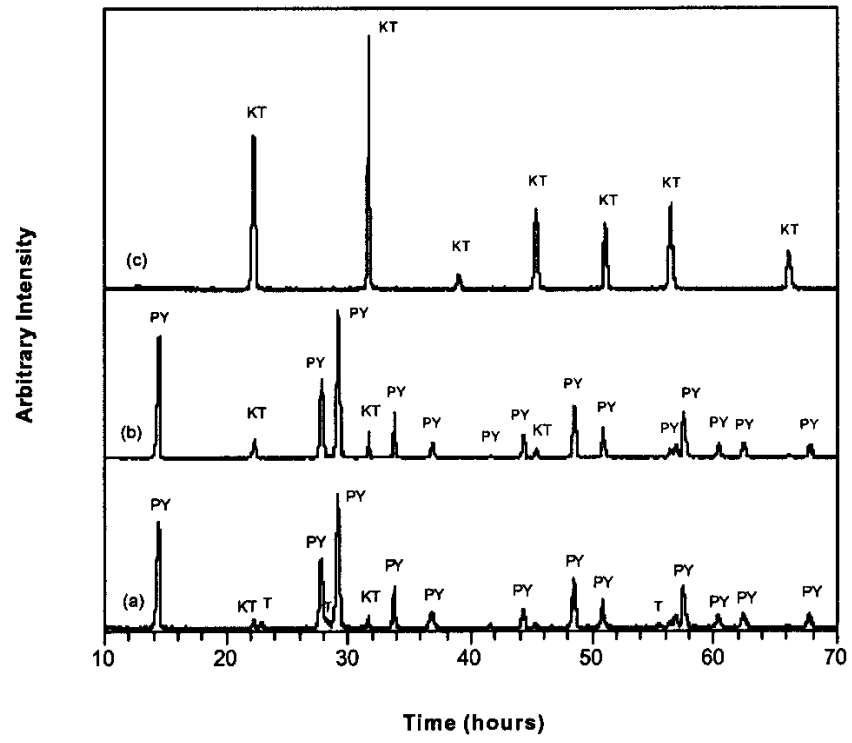

FIG. 1. XRD patterns of powders synthesized at $200{ }^{\circ} \mathrm{C}$ in $7 \mathrm{M} \mathrm{KOH}$ after (a) $2 \mathrm{~h}$, primarily PY; (b) $4 \mathrm{~h}$, primarily PY with increased quantity of $\mathrm{KT}$; (c) $24 \mathrm{~h}$, entirely $\mathrm{KT}\left(\mathrm{KT}, \mathrm{KTaO}_{3}\right.$; PY, pyrochlore; $\mathrm{T}, \mathrm{Ta}_{2} \mathrm{O}_{5}$ ).

and after long reaction periods. Notably, synthesis in $15 \mathrm{M} \mathrm{KOH}$ (as observed at temperatures and time intervals reported in Table I) yielded the perovskite without evidence of the intermediate pyrochlore phase. The perovskite powders produced at this high $\mathrm{KOH}$ concentration at 150 and $200{ }^{\circ} \mathrm{C}$ were determined to have an increased lattice parameter of $4.000 \AA$. Also, the $15 \mathrm{M} / 150{ }^{\circ} \mathrm{C}$ powder had a $\mathrm{K} / \mathrm{Ta}$ ratio of 0.93 , and the particles were cubic in shape but smaller and more uniform in size than the perovskite particles synthesized at $7 \mathrm{M} \mathrm{KOH}$ [see Figs. 2(b) and 2(c)].

When a solution of $7 \mathrm{M} \mathrm{KOH}$ and $8 \mathrm{M} \mathrm{CsOH}$ (this yielded an $\mathrm{OH}^{-}$concentration of $15 \mathrm{M}$ while keeping the $\mathrm{K}^{+}$concentration at $7 \mathrm{M}$ ) was used at a processing temperature of $150{ }^{\circ} \mathrm{C}$, no intermediate pyrochlore was observed, although the perovskite phase was still obtained, similar to the case when only $15 \mathrm{M} \mathrm{KOH}$ is used (see Table I, $\left.150{ }^{\circ} \mathrm{C}, 15 \mathrm{M} \mathrm{KOH}\right)$. Conversely, only pyrochlore was present after $16 \mathrm{~h}$ when the synthesis was performed at $200{ }^{\circ} \mathrm{C}$ and $4 \mathrm{M} \mathrm{KOH}$. (This powder had octahedral particles, a lattice parameter of $10.619 \AA$, and a K/Ta ratio of 0.46.) These observations suggest that the hydroxyl ion concentration was the critical parameter promoting the formation of the pyrochlore phase.

\section{B. Perovskite powders}

FTIR spectroscopy shown in Fig. 3 for perovskite powders synthesized at $7 \mathrm{M} / 200{ }^{\circ} \mathrm{C} / 24 \mathrm{~h}$ and $15 \mathrm{M} / 150{ }^{\circ} \mathrm{C} / 4 \mathrm{~h}$, hereafter referred to as the $7 \mathrm{M}$ and $15 \mathrm{M}$ perovskite powders, respectively, revealed a broad band from 2800 to $3700 \mathrm{~cm}^{-1}$. This broadness is 


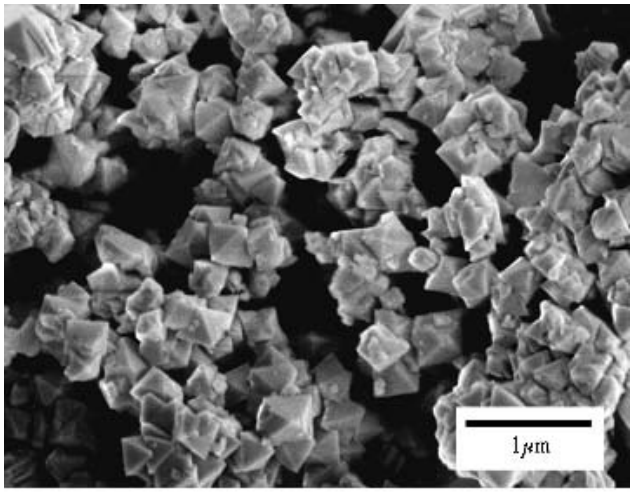

(a)

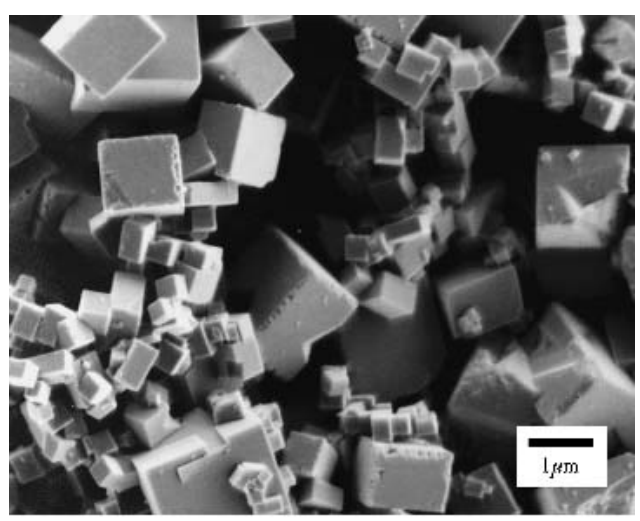

(b)

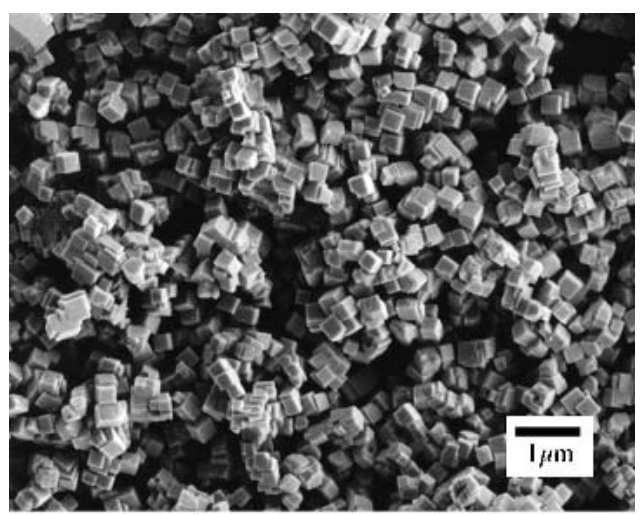

(c)

FIG. 2. SEM micrographs of (a) pyrochlore powder synthesized at $7 \mathrm{M} / 200{ }^{\circ} \mathrm{C}$ after $2 \mathrm{~h}$, (b) perovskite powder synthesized at $7 \mathrm{M} / 200{ }^{\circ} \mathrm{C}$ after $24 \mathrm{~h}$, and (c) perovskite powder synthesized at $15 \mathrm{M} / 150{ }^{\circ} \mathrm{C}$ after $4 \mathrm{~h}$.

normally ascribed to the overlap of $\mathrm{O}-\mathrm{H}$ stretching vibrations of hydroxyl groups and water molecules. In comparison with the $\mathrm{O}-\mathrm{H}$ stretching band, the band at approximately $1650 \mathrm{~cm}^{-1}$, ascribed to the bending vibration of $\mathrm{H}_{2} \mathrm{O}$, was relatively less significant for both powders. ${ }^{1} \mathrm{H}$ MAS NMR data shown in Fig. 4(a) revealed only one significant peak at $5.47 \mathrm{ppm}$ for the $7 \mathrm{M}$ perovskite powder and similarly at $5.46 \mathrm{ppm}$ for the $15 \mathrm{M}$ perovskite powder (latter not shown). The magnitude of the shift is typical of that observed for internally incorporated protons (as opposed to surface $\mathrm{H}_{2} \mathrm{O}$ or surface hydroxyl groups) with $\mathrm{OH}^{-}$stretching frequencies around $3400 \mathrm{~cm}^{-1} .{ }^{11}$ The total integrated ${ }^{1} \mathrm{H}$ MAS NMR signal for the $15 \mathrm{M}$ perovskite powder was 4.2 times that for the $7 \mathrm{M}$ perovskite powder on a per gram basis.

Mass spectrometry assisted TGA data shown in Fig. 5 taken between room temperature and $900{ }^{\circ} \mathrm{C}$ revealed a total weight loss of $0.68 \mathrm{wt} \%$ for the $7 \mathrm{M}$ perovskite powder and $3.1 \mathrm{wt} \%$ for the $15 \mathrm{M}$ perovskite powder, 4.6 times greater than the former. In both cases, mass spectrometry ascribed the weight loss to the evolution of water. This agrees quite well with earlier observations by ${ }^{1} \mathrm{H}$ NMR that the concentration of internally incorporated protons for the $15 \mathrm{M}$ powder was 4.2 times greater than that for the $7 \mathrm{M}$ powder. Also, approximately $68 \%$ of the weight loss occurred before $350{ }^{\circ} \mathrm{C}$ for the $15 \mathrm{M}$ perovskite powder, compared with only $33 \%$ for the $7 \mathrm{M}$ perovskite powder. After the TGA treatment, XRD showed that the lattice parameter of the $15 \mathrm{M}$ perovskite powder had decreased from 4.000 to $3.992 \AA$, similar to the one observed in the as-synthesized condition for the $7 \mathrm{M}$ powder and close to the theoretical value of $3.989 \AA$, as noted in Sec. III. A.

\section{Pyrochlore powders}

Figure 6 shows the FTIR spectrum for the pyrochlore powder synthesized at $4 \mathrm{M} / 200{ }^{\circ} \mathrm{C} / 16 \mathrm{~h}$; it also exhibits the broad O-H stretching band at 2800 to $3700 \mathrm{~cm}^{-1}$. In contrast to the perovskite powders, the band at $1635 \mathrm{~cm}^{-1}$ characteristic of the bending mode of $\mathrm{H}_{2} \mathrm{O}$ was more significant. The spectrum for the material synthesized at $7 \mathrm{M} / 200{ }^{\circ} \mathrm{C} / 2 \mathrm{~h}$, containing primarily pyrochlore, was similar, consistent with the presence of $\mathrm{H}_{2} \mathrm{O}$ and hydroxyl groups. The ${ }^{1} \mathrm{H}$ MAS NMR spectra for the $4 \mathrm{M}$ pyrochlore powder, shown in Fig. 4(b), had two peaks, indicating the presence of at least two types of protons incorporated into the structure.

The TGA data in Fig. 7 for the pyrochlore powders showed that all measurable weight loss occurred below $450{ }^{\circ} \mathrm{C}$. The total weight loss for the $4 \mathrm{M}$ pyrochlore powder was $6.45 \mathrm{wt} \%$ while that for the $7 \mathrm{M}$ pyrochlore powder was $6.60 \mathrm{wt} \%$. Concurrent mass spectrometry confirmed that these weight losses were associated with the evolution of water.

In situ hot stage XRD $\left(3 \times 10^{-4}\right.$ torr vacuum $)$ of the $4 \mathrm{M}$ powder showed that there was a decrease in lattice parameter between 100 and $200{ }^{\circ} \mathrm{C}$ [Fig. 8(a)]. The contracted lattice was retained upon heating to $320^{\circ} \mathrm{C}$ and also after cooling to room temperature. Interestingly, the lattice appeared to have expanded back to its original dimensions after the powder was exposed to laboratory air overnight $(\approx 18 \mathrm{~h})$. In situ hot stage XRD for the $7 \mathrm{M}$ pyrochlore [Fig. 8(b)] showed that the pyrochlore lattice 
TABLE I. Phases present after different processing temperatures and $\mathrm{KOH}$ concentrations.

\begin{tabular}{|c|c|c|c|c|c|c|c|}
\hline Temperature $\left({ }^{\circ} \mathrm{C}\right)$ & Concentration (M) & $2 \mathrm{~h}$ & $4 \mathrm{~h}$ & $8 \mathrm{~h}$ & $16 \mathrm{~h}$ & $24 \mathrm{~h}$ & $48 \mathrm{~h}$ \\
\hline \multirow[t]{2}{*}{100} & 7 & & & & $\mathrm{~T}, \mathrm{PY}$ & & \\
\hline & 15 & & $\mathrm{~T}, \mathrm{KT}$ & & $\mathrm{T}, \mathrm{KT}$ & & \\
\hline \multirow[t]{4}{*}{150} & 7 & & $\mathrm{~T}, \mathrm{PY}$ & & $\mathrm{T}, \mathrm{PY}, \mathrm{KT}$ & & PY, KT \\
\hline & 10 & $\mathrm{~T}, \mathrm{PY}$ & & & & & PY, KT \\
\hline & 12 & $\mathrm{~T}, \mathrm{PY}$ & & & & & PY, KT \\
\hline & 15 & $\mathrm{~T}, \mathrm{KT}$ & KT & & & & \\
\hline \multirow[t]{2}{*}{175} & 7 & & $\mathrm{~T}, \mathrm{PY}, \mathrm{KT}$ & $\mathrm{PY}, \mathrm{KT}$ & PY, KT & & PY, KT \\
\hline & 4 & & $\mathrm{~T}, \mathrm{PY}$ & PY & PY & & \\
\hline \multirow[t]{2}{*}{200} & 7 & $\mathrm{~T}, \mathrm{PY}, \mathrm{KT}$ & $\mathrm{T}, \mathrm{PY}, \mathrm{KT}$ & PY, KT & $\mathrm{PY}, \mathrm{KT}$ & KT & \\
\hline & 15 & & KT & & & & \\
\hline
\end{tabular}

Key: T, $\mathrm{Ta}_{2} \mathrm{O}_{5} ; \mathrm{KT}, \mathrm{KTaO}_{3}$; PY, Pyrochlore; Blanks, no data collected.

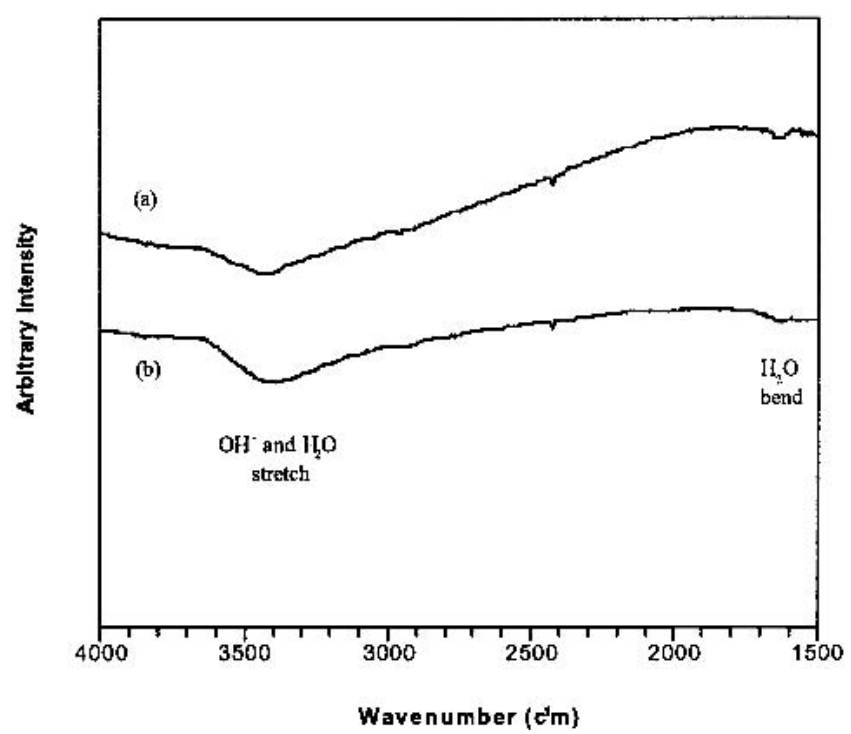

FIG. 3. FTIR spectra for perovskite powders synthesized (a) at $200{ }^{\circ} \mathrm{C}$ in $7 \mathrm{M} \mathrm{KOH}$ for $24 \mathrm{~h}$, and (b) at $150{ }^{\circ} \mathrm{C}$ in $15 \mathrm{M} \mathrm{KOH}$ after $4 \mathrm{~h}$.

began contracting at $100{ }^{\circ} \mathrm{C}$. Like the $4 \mathrm{M}$ powder, the contracted lattice was retained after cooling from $320^{\circ} \mathrm{C}$ to room temperature but expanded back to its original volume after the $7 \mathrm{M}$ powder was exposed to air overnight.

\section{DISCUSSION}

\section{A. Perovskite powders}

The high degree of $\mathrm{K} / \mathrm{Ta}$ nonstoichiometry and proton incorporation observed for the perovskite powders has implications for the defect chemistry and dehydration mechanism. The protons may be present either in the form of hydroxyl groups (residing on sites normally occupied by oxygen atoms) or as $\mathrm{H}_{2} \mathrm{O}$ molecules (residing in currently unspecified locations). The former is common for many perovskites and has, for example, been observed for potassium tantalate perovskite crystals
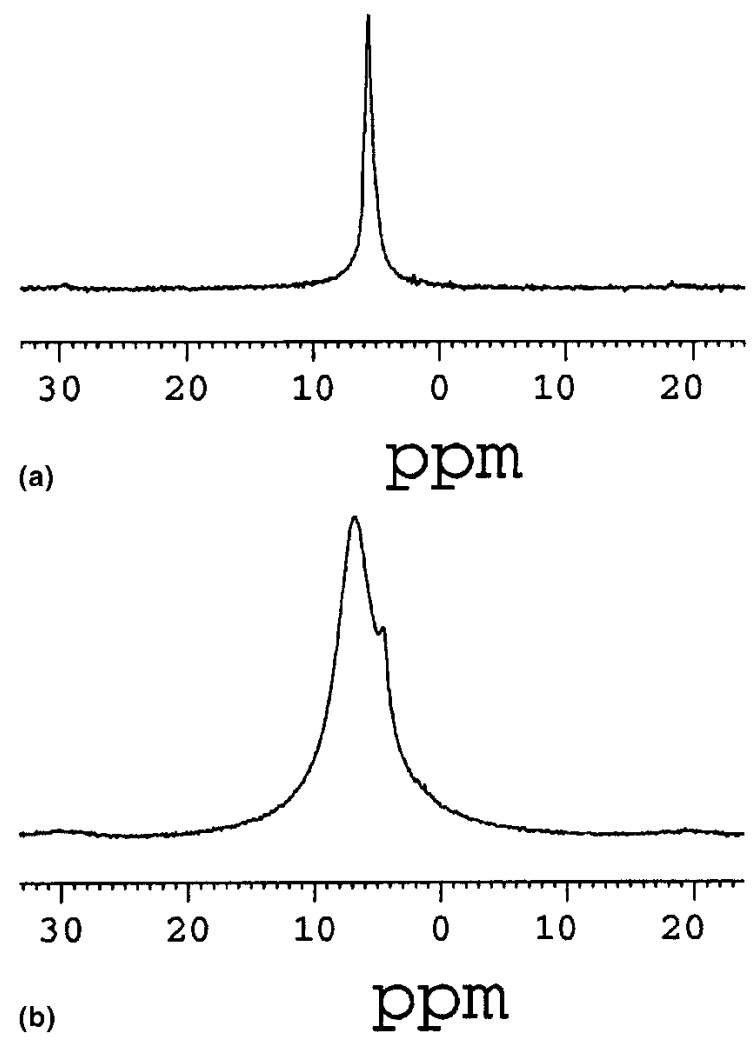

FIG. 4. ${ }^{1} \mathrm{H}$ NMR spectra for (a) perovskite powder synthesized at $200{ }^{\circ} \mathrm{C}$ in $7 \mathrm{M} \mathrm{KOH}$ for $24 \mathrm{~h}$, and (b) pyrochlore powder synthesized at $200{ }^{\circ} \mathrm{C}$ in $4 \mathrm{M} \mathrm{KOH}$ after $16 \mathrm{~h}$.

grown from the melt. ${ }^{12}$ To account for these two possible modes of proton incorporation and the cation vacancies that likely accompany hydroxyl group formation, ${ }^{13-16}$ the chemical formula of potassium tantalate hydrate may be written as $\mathrm{K}_{x} \mathrm{Ta}_{y} \mathrm{O}_{3-z}(\mathrm{OH})_{z} \cdot n \mathrm{H}_{2} \mathrm{O}$, where $x+5 y+z=6$ is required for overall charge neutrality. The presence of cation vacancies as charge compensation defects is experimentally supported by the work of Shi and coworkers, ${ }^{6}$ who observed by FTIR and electron paramagnetic resonance that the concentration of $\mathrm{Ba}^{2+}$ vacancies increased with increasing $\mathrm{OH}^{-}$concentration in $\mathrm{BaTiO}_{3}$. 
Subsequent to synthesis, complete dehydration, as recorded in the TGA experiments, involves the loss of $(z / 2+n)$ molecules of water, i.e.,

$$
\mathrm{K}_{x} \mathrm{Ta}_{y} \mathrm{O}_{3-z}(\mathrm{OH})_{z} \cdot n \mathrm{H}_{2} \mathrm{O} \rightarrow \mathrm{K}_{x} \mathrm{Ta}_{y} \mathrm{O}_{3-z / 2}+(z / 2+n) \mathrm{H}_{2} \mathrm{O} \text {. }
$$

Thus, the magnitude of the weight loss provides useful data in helping to establish the defect chemistry.

To set the boundaries on the concentration of cation vacancies in the perovskite powders, two limiting cases will be considered. In case 1 , cation vacancies are taken to be present on both potassium and tantalum sites, the $\mathrm{K} / \mathrm{Ta}$ ratio is given by the chemical analysis (that is, $x=0.93 y$ ), and all protons are taken to be incorporated in the form of hydroxyl groups such that $n=0$. In

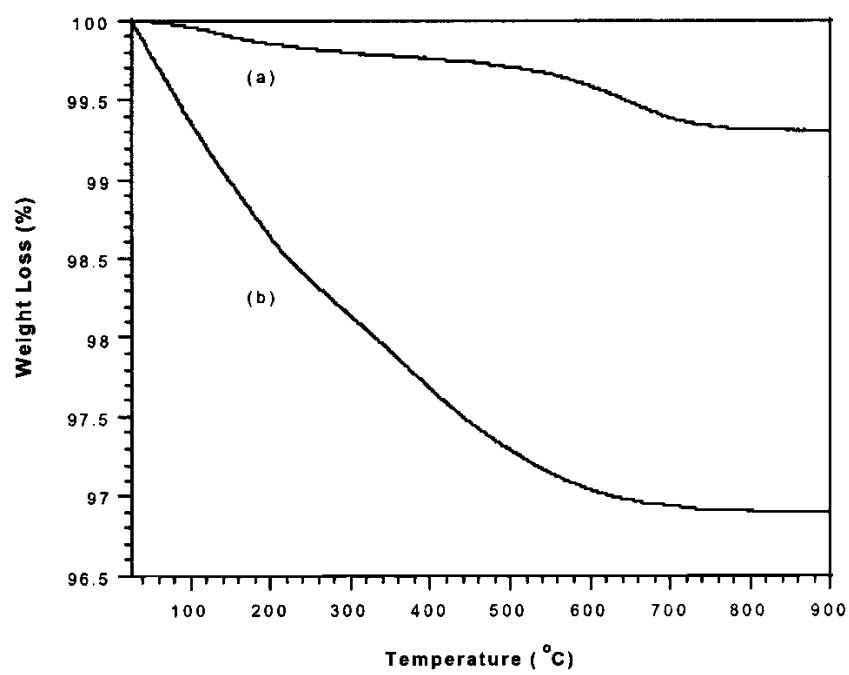

FIG. 5. TG curves for perovskite powders synthesized at (a) $7 \mathrm{M}$ $\mathrm{KOH} / 200{ }^{\circ} \mathrm{C}(24 \mathrm{~h})$ and (b) $15 \mathrm{M} \mathrm{KOH} / 150{ }^{\circ} \mathrm{C}(4 \mathrm{~h})$.

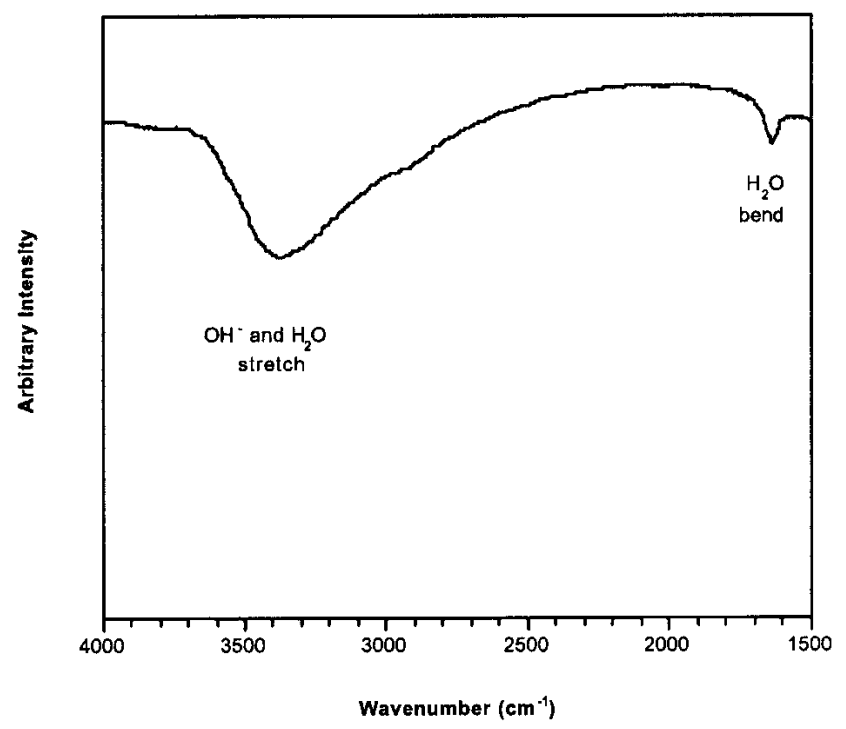

FIG. 6. FTIR spectra for pyrochlore powders synthesized at $200{ }^{\circ} \mathrm{C}$ in $4 \mathrm{M} \mathrm{KOH}$ after $16 \mathrm{~h}$. case 2, cation vacancies are allowed only on potassium sites, such that $y=1$ and $x=0.93$, but both hydroxyl groups and water molecules contribute to proton incorporation. Using these boundary conditions, the charge neutrality condition, and the value of $(z / 2+n)$ implied by the weight loss measurements, all the stoichiometric parameters can be determined. The results for both cases for the $7 \mathrm{M}$ and $15 \mathrm{M}$ perovskite powders are summarized in Table II. Also given is the concentration of oxygen vacancies generated during dehydration for the two cases.

To establish which of these two cases more closely reflects the physical reality, we consider the NMR and FTIR results and the plausibility of the implied defect concentrations. The NMR spectra (Fig. 4) for both perovskite powders exhibited only one peak, and this result is consistent with the presence of a single type of proton, whereas the FTIR results (Fig. 3) showing a very weak $\mathrm{H}_{2} \mathrm{O}$ bending band suggest this proton exists in the form of $\mathrm{OH}^{-}$rather than $\mathrm{H}_{2} \mathrm{O}$. Thus, both sets of results are consistent with case 1 for both perovskite powders. The type and concentration of defects implied by case 1 are quite plausible for the perovskite powder synthesized under $7 \mathrm{M} \mathrm{KOH}$, but not for the powder synthesized under $15 \mathrm{M} \mathrm{KOH}$. Specifically, case 1 implies a $9 \%$ vacancy concentration on the $\mathrm{K}$ sites and a $2 \%$ vacancy concentration on the Ta sites for the $7 \mathrm{M}$ perovskite powder. In contrast, the implied vacancy concentrations are $19 \%$ and $13 \%$, respectively, for the $15 \mathrm{M}$ perovskite powder (assuming case 1). It is likely that potassium tantalate can tolerate high concentrations of potassium (A site) vacancies while maintaining the perovskite structure, as implied by the existence of $\mathrm{HTaO}_{3}$. This compound, like the perovskite, is composed of a $\mathrm{ReO}_{3}$-type cubic framework of corner sharing $\mathrm{TaO}_{6}$

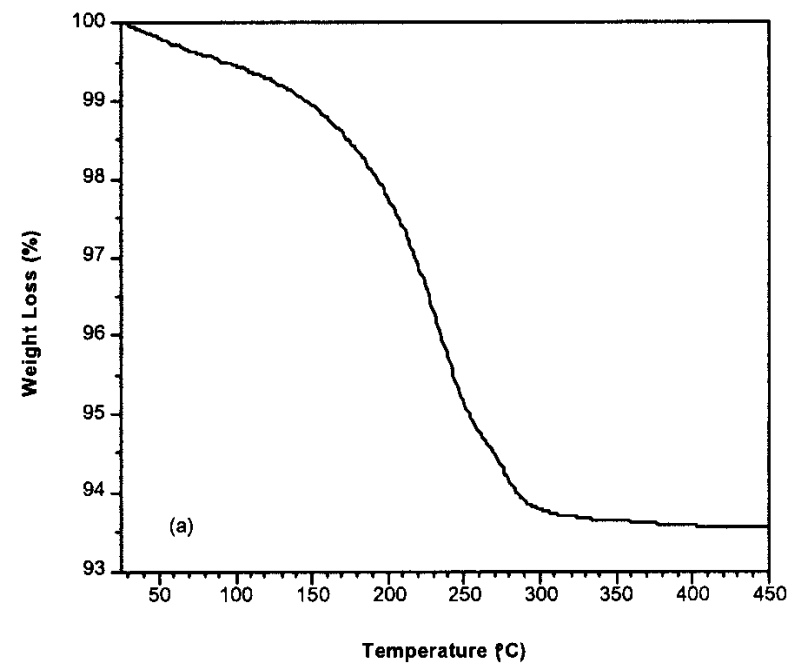

FIG. 7. TG curve for pyrochlore powder synthesized at $200{ }^{\circ} \mathrm{C}$ in $4 \mathrm{M}$ $\mathrm{KOH}$ after $16 \mathrm{~h}$. 
[or $\mathrm{Ta}(\mathrm{O}, \mathrm{OH})_{6}$ ] octahedra but differs in that the perovskite A sites are completely vacant. ${ }^{17}$ On the other hand, it is not clear if the perovskite framework can be maintained in the presence of B site vacancy concentrations as

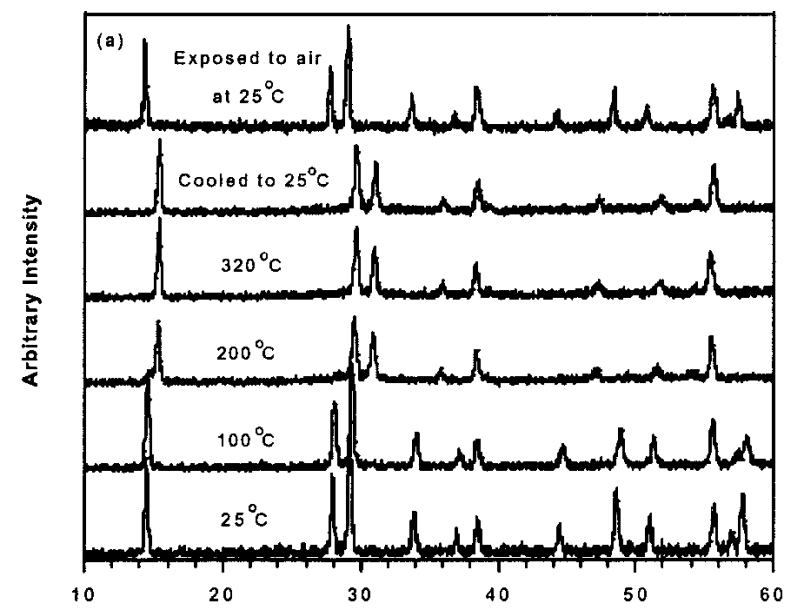

(a)

20

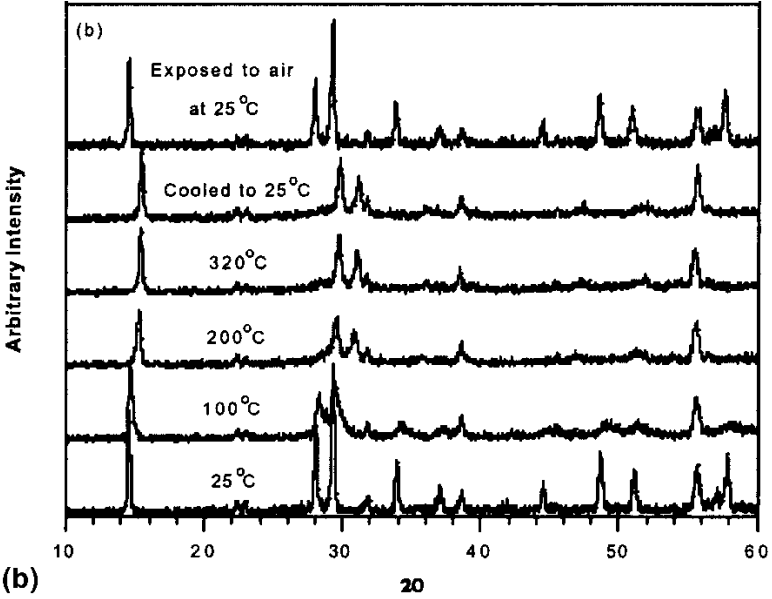

FIG. 8. In situ hot stage XRD $\left(3 \times 10^{-4}\right.$ torr vacuum $)$ patterns for pyrochlore powders (a) $4 \mathrm{M}$ and (b) $7 \mathrm{M}$ (the peaks at $2 \theta \approx 38.5^{\circ}$ and $55.5^{\circ}$ are from the tantalum specimen holder).

TABLE II. Experimental results and defect concentrations for perovskite powders.

\begin{tabular}{|c|c|c|}
\hline Synthesis conditions & $7 \mathrm{M} / 24 \mathrm{~h} / 200^{\circ} \mathrm{C}$ & $15 \mathrm{M} / 4 \mathrm{~h} / 150^{\circ} \mathrm{C}$ \\
\hline $\mathrm{K} / \mathrm{Ta}$ ratio & 0.93 & 0.93 \\
\hline Lattice parameter & $3.991 \AA$ & $4.000 \AA$ \\
\hline Weight loss (fraction) & 0.0068 & 0.031 \\
\hline \multicolumn{3}{|l|}{ Case 1 (only $\mathrm{OH}^{-}, n=0$ ) } \\
\hline K occupancy, $x$ & 0.91 & 0.81 \\
\hline Ta occupancy, $y$ & 0.98 & 0.87 \\
\hline $\mathrm{OH}^{-}$per $\mathrm{KTaO}_{3}$ unit, $z$ & 0.19 & 0.82 \\
\hline Fraction of $\mathrm{O}$ sites vacant & 0.032 & 0.14 \\
\hline \multicolumn{3}{|l|}{ Case 2 (full Ta occupancy) } \\
\hline K occupancy, $x$ & 0.93 & 0.93 \\
\hline $\mathrm{OH}^{-}$per $\mathrm{KTaO}_{3}$ unit, $z$ & 0.07 & 0.07 \\
\hline $\mathrm{H}_{2} \mathrm{O}$ per $\mathrm{KTaO}_{3}$ unit, $n$ & 0.066 & 0.44 \\
\hline Fraction of $\mathrm{O}$ sites vacant & 0.012 & 0.012 \\
\hline
\end{tabular}

high as $13 \%$ (case 1, $15 \mathrm{M}$ perovskite powder). Therefore, while case 1 is suitable for describing completely the defect chemistry of the $7 \mathrm{M}$ perovskite powder, it is improbable for the $15 \mathrm{M}$ perovskite powder.

In considering the alternative, case 2 , it is necessary to establish where the $\mathrm{H}_{2} \mathrm{O}$ molecules might reside within the perovskite structure. Given the charge neutrality of the water molecule, this species is equally likely to occupy a site normally filled by either anions or cations; it is proposed that any $\mathrm{H}_{2} \mathrm{O}$ resides on the $\mathrm{A}$ (or potassium) sites, based primarily on the similarity in size of $\mathrm{K}$ and $\mathrm{H}_{2} \mathrm{O}$. This location of the water molecule can be reconciled with the NMR results, in which a single type of proton environment was revealed. The protons within potassium tantalate, as with any oxide material, will participate in the formation of hydrogen bonds between two neighboring oxygen atoms, and the chemical shift of the NMR signal is primarily established by the distance between those two oxygen atoms. ${ }^{11}$ In the case of $\mathrm{OH}^{-}$protons, in which the hydroxyl group resides on a normal oxide ion site, the nearest oxygen atom is at a distance of $a / \sqrt{2} \AA$ (where $a$ is the lattice parameter). This distance is also precisely the $\mathrm{K}-\mathrm{O}$ distance, and a similar hydrogen bond can be formed between $\mathrm{H}_{2} \mathrm{O}$ located on a potassium site and its nearest oxygen neighbor. Thus, the two different species, $\mathrm{OH}^{-}$and $\mathrm{H}_{2} \mathrm{O}$, can produce similar local environments for the protons and thereby result in the presence of only one peak in the NMR spectra.

In the extreme of case 2, the concentration of potassium vacancies implied is $7 \%$ (for both powders). While this value is sufficient to accommodate all of the water molecules of the $7 \mathrm{M}$ perovskite powder $(n=0.066)$ it is far less than what is required to accommodate all of the water molecules of the $15 \mathrm{M}$ perovskite powder, for which $n=0.44$. Thus, it is impossible for case 2 to adequately describe the defect chemistry of the $15 \mathrm{M}$ perovskite powder. In light of the discussion above, we conclude that the scenario for the $15 \mathrm{M}$ perovskite powder is between cases 1 and 2, and that the structure contains both potassium and tantalum vacancies as well as hydroxyl groups and water molecules (limited to the fraction of potassium vacancies, i.e., $n=1-x$ ). An estimate of the defect concentrations in this intermediate case can be established for the experimental conditions $(\mathrm{K} / \mathrm{Ta}$ ratio $=0.93$, dehydrated water loss of $3.1 \%)$ for the condition where $x=0.85, y=0.92$, and $z=0.57$, namely, a dehydrated formula of $\mathrm{K}_{0.85} \mathrm{Ta}_{0.92} \mathrm{O}_{2.72}$.

In addition to the two hydrogen containing species, $\mathrm{OH}^{-}$groups on oxygen sites and $\mathrm{H}_{2} \mathrm{O}$ molecules on potassium sites, one can also consider the possibility of proton incorporation via $\mathrm{H}_{3} \mathrm{O}^{+}$groups, presumably also on potassium ion sites. From local charge balance considerations, such species are, perhaps, more plausible than $\mathrm{H}_{2} \mathrm{O}$ on $\mathrm{K}$ sites. However, hydronium ions would be 
indistinguishable from hydroxyl groups in terms of both the dehydration reaction (1) and the NMR spectra, as discussed earlier. Thus, it is impossible to establish from the experiments carried out here, whether or not they exist in potassium niobate. In any case, their presence would not change the overall balance between the concentration of $\mathrm{K}, \mathrm{Nb}$, and $\mathrm{O}$ atoms required for consistency with the EDS and TGA data. We note, however, that the presence of hydronium ions is more likely for the $15 \mathrm{M}$ perovskite than for the $7 \mathrm{M}$ material because of the greater weight loss in the former.

In all, our analysis indicates that the concentration of defects is significantly greater in the $15 \mathrm{M}$ perovskite powder than in the $7 \mathrm{M}$. The $15 \mathrm{M}$ perovskite powder also has the larger lattice constant, $4.000 \AA$, as compared to $3.991 \AA$. This result is consistent with observations for hydrothermally synthesized $\mathrm{BaTiO}_{3}$ powders that the lattice parameter increases with increasing concentration of point defects like cation vacancies and hydroxyl groups. ${ }^{16,18}$ It has been proposed that these defects reduce the Coulomb attractive forces between the ions, leading to an expansion of the lattice.

The dehydration reaction [reaction (1)] involves both the loss of molecular water and water present in the form of hydroxyl groups. For the case of the loss of hydroxyl groups, oxygen vacancies are generated for charge compensation, as implied above, and stated more explicitly according to ${ }^{14,15}$

$$
2\left(\mathrm{OH}_{\mathrm{o}}^{\bullet}\right) \Leftrightarrow \mathrm{V}_{\mathrm{o}}^{\bullet \bullet}+\mathrm{O}_{\mathrm{o}}+\mathrm{H}_{2} \mathrm{O}
$$

The removal of the hydroxyl groups from the interior of the structure requires the concurrent diffusion of oxygen ions and protons. For undoped perovskites, oxygen is sufficiently mobile only above $600{ }^{\circ} \mathrm{C} .{ }^{19}$ For the protonic conductor, barium zirconate, which is deliberately doped to produce oxygen vacancies, the onset of dehydration is reported to occur at lower temperatures, i.e., between 350 to $550{ }^{\circ} \mathrm{C}^{20}$ In contrast, for the perovskite powders studied here, $68 \%$ and $33 \%$ of the weight loss for the $15 \mathrm{M}$ and $7 \mathrm{M}$ perovskite powders, respectively, occur below $350{ }^{\circ} \mathrm{C}$. This occurs despite the fact that all oxygen sites in the hydrated perovskite [e.g., $\mathrm{K}_{0.85} \mathrm{Ta}_{0.92} \mathrm{O}_{2.43}(\mathrm{OH})_{0.57} \cdot 0.15 \mathrm{H}_{2} \mathrm{O}$ ] are expected to be filled with oxygen or hydroxyl ions while the potassium sites are filled with potassium ions or water molecules. As the perovskite structure is a cubic close-packed structure composed of potassium and oxygen ions, this implies that there is no path for the diffusion of water molecules out of the structure.

To account for the rapid loss of water at low temperatures, it is proposed that water molecules that sit on potassium sites at the surface are lost first. In addition, reaction (2) taking place at the surface leads to the generation and loss of additional water molecules. These two processes create the required vacant sites for the subsequent diffusion of water molecules from beneath the surface. The boundary between the region close to the surface that contains vacant potassium and oxygen sites and the interior region with hydroxyl groups and potassium sites filled with water molecules then moves progressively inward, analogous to a drying front, as water molecules diffuse to the surface. Note that reaction (2) can also take place internally near a vacant potassium site. In addition, since the water molecule is a neutral species with a Coulombic radius of $1.37 \AA{ }^{21}$ the molecule could diffuse to the surface by hopping through either the vacant potassium sites $(r=1.60 \AA)^{22}$ or the vacant oxygen sites (radius, $r=1.42 \AA$ ).

\section{B. Pyrochlore powders}

The general formula for a normal pyrochlore can be written as $\mathrm{A}_{2} \mathrm{~B}_{2} \mathrm{O}_{6} \mathrm{O}^{\prime}$ with four crystallographically nonequivalent atom sites; the structure can be viewed as interpenetrating networks of $\mathrm{B}_{2} \mathrm{O}_{6}$ and $\mathrm{A}_{2} \mathrm{O}^{\prime} .^{23}$ In this description, the $\mathrm{B}_{2} \mathrm{O}_{6}$ network is made up of a threedimensional array of corner-shared $\mathrm{BO}_{6}$ octahedra interpenetrated by zig-zag chains of $\mathrm{A}_{2} \mathrm{O}^{\prime}$. As it is the $\mathrm{B}_{2} \mathrm{O}_{6}$ network that is essential for stabilization of the structure, vacancies can exist at both $\mathrm{A}^{2}$ and $\mathrm{O}^{\prime}$ sites without changing the basic framework. ${ }^{23}$ Vacancies at the cation and/or anion sites give rise to the defect pyrochlore structures of $\mathrm{A}_{2} \mathrm{~B}_{2} \mathrm{O}_{6} \square^{\prime}$ or $\mathrm{A} \square \mathrm{B}_{2} \mathrm{O}_{6} \square^{\prime},{ }^{24,25}$ many of which are found hydrated. ${ }^{8,24,26-29}$

As the $\mathrm{K} / \mathrm{Ta}$ ratio of the pyrochlore phase found in this study is $\approx 0.5$, its structure appears to be of the second type, $\mathrm{A} \square \mathrm{B}_{2} \mathrm{O}_{6} \square$ '. Duan and co-workers, who also synthesized the pyrochlore phase at $4.4 \mathrm{M} \mathrm{KOH} / 200{ }^{\circ} \mathrm{C} / 48 \mathrm{~h}$ and also observed a $\mathrm{K} / \mathrm{Ta}$ ratio of $\approx 0.5$, proposed that one of the oxygen atoms in the $\mathrm{B}_{2} \mathrm{O}_{6}$ unit is substituted by a hydroxyl ion and furthermore that the compound is hydrated, thereby giving a formula of $\mathrm{K} \square \mathrm{Ta}_{2} \mathrm{O}_{5}(\mathrm{OH}) \square \cdot n \mathrm{H}_{2} \mathrm{O}$, where $\square$ depicts the two sites that might be occupied by the water molecules. The ${ }^{1} \mathrm{H}$ MAS NMR spectra for the $4 \mathrm{M}$ pyrochlore powder synthesized in this study, shown in Fig. 4(b), indicates the presence of at least two types of protons in the structure and provides support for such a formula. In addition, FTIR studies (Fig. 6) confirm the presence of water and hydroxyl groups. When $\mathrm{K} / \mathrm{Ta}=0.5$ is assumed for simplicity and

$$
\begin{aligned}
& \mathrm{K} \square \mathrm{Ta}_{2} \mathrm{O}_{5}(\mathrm{OH}) \square \cdot n \mathrm{H}_{2} \mathrm{O} \rightarrow \\
& \mathrm{K} \square \mathrm{Ta}_{2} \mathrm{O}_{5.5} \square+(n+0.5) \mathrm{H}_{2} \mathrm{O}
\end{aligned}
$$

a value of $n=1.4$ is calculated for the measured weight change $(\approx 6.5 \%)$. This amount of water can be accommodated in the vacant potassium and oxygen sites denoted by $\square$. 
The appearance of the perovskite rather than pyrochlore phase at high $\mathrm{OH}^{-}$concentrations is noteworthy. Neglecting for the moment the water of hydration, one could write the hydrothermal reaction as

$\mathrm{Ta}_{2} \mathrm{O}_{5}+\mathrm{KOH} \rightarrow \mathrm{KTa}_{2} \mathrm{O}_{5}(\mathrm{OH})$ (defect pyrochlore) ,

which then further reacts at high $\mathrm{OH}^{-}$concentrations to form the perovskite phase

$\mathrm{KTa}_{2} \mathrm{O}_{5}(\mathrm{OH})+\mathrm{KOH} \rightarrow 2 \mathrm{KTaO}_{3}$ (perovskite) $+\mathrm{H}_{2} \mathrm{O}$

At lower $\mathrm{OH}^{-}$concentrations (e.g., $4 \mathrm{M} \mathrm{KOH}$ ) the 1:2 pyrochlore appears to be the only stable phase (the potassium concentration does not appear to be controlling since the perovskite phase was produced when substantial amounts of $\mathrm{KOH}$ were replaced by $\mathrm{CsOH}$ ). At high $\mathrm{OH}^{-}$concentrations, the pyrochlore is only an intermediate phase [via reaction (4)], and the perovskite is the stable phase [formed via reaction (5)].

For the K/Ta ratio to increase from the 0.51 for the pyrochlore powder to 0.93 observed for the perovskite powder, it is most likely that the conversion occurs via a dissolution-reprecipitation mechanism. A consequence of this is that even after all the precursor $\mathrm{Ta}_{2} \mathrm{O}_{5}$ powder has dissolved, soluble tantalum oxide species continue to be supplied from the dissolution of the pyrochlore. As such, it is probable that nucleation occurs over an extended period of time, concurrent with growth, leading to the larger particle size distribution observed for the $7 \mathrm{M}$ perovskite powders. Following similar reasoning, it is then probable that the nucleation of the $15 \mathrm{M}$ perovskite powder occurs over a much shorter period of time since its synthesis does not involve an intermediate pyrochlore, and this leads to the narrower particle size distribution observed [compare Figs. 2(b) and 2(c)].

The ease with which water can diffuse into and out of $\mathrm{K} \square \mathrm{Ta}_{2} \mathrm{O}_{5}(\mathrm{OH}) \square \cdot n \mathrm{H}_{2} \mathrm{O}$ can be understood in terms of its structure, which is permeated by three-dimensional tunnels (associated with the vacancies $\square$ on both the cation and anion sites). This defect pyrochlore is known as an octahedral molecular sieve, so named because the basic building block is a $\mathrm{TaO}_{6}$ octahedron instead of the tetrahedra found in zeolite molecular sieves. ${ }^{8}$ XRD, neutron diffraction, and NMR experiments on these pyrochlore structures have all demonstrated that the water molecules and hydroxyl protons reside within the tunnels. ${ }^{8,28,29}$ In addition, Brunauer-Emmett-Teller adsorption measurements have shown that the dehydrated $\mathrm{KTa}_{2} \mathrm{O}_{5}(\mathrm{OH})$ defect pyrochlore maintains its open structure at $300{ }^{\circ} \mathrm{C}$, while in situ hot stage XRD in this study and by others ${ }^{27}$ have shown that the crystal structure is stable to at least $400{ }^{\circ} \mathrm{C}$. Using in situ diffuse reflectance FTIR, Duan et al. observed that heating the defect pyrochlore powder up to $250{ }^{\circ} \mathrm{C}$ caused an almost complete disappearance of the bending vibrations of $\mathrm{H}_{2} \mathrm{O}$ at 1600 $1650 \mathrm{~cm}^{-1}$ although the broad band due to $\mathrm{O}-\mathrm{H}$ stretching was still present. ${ }^{8}$ As such, the contraction of the pyrochlore lattice upon heating, as observed by in situ hot stage XRD in this study, is largely due to the loss of molecular water from the channels, which, upon readsorption at room temperature, leads to an expansion of the lattice.

The driving force for adsorption of water in molecular sieves is the formation of ion-dipole pairs, in this case between water molecules and potassium ions, and hydrogen bonding between water molecules and oxygen of the $\mathrm{B}_{2} \mathrm{O}_{6}$ framework (the $48 f$ oxygen). ${ }^{30}$ The hydrogen bonding between $48 f$ oxygen and water molecules reduces the Coulomb attractive forces between ions in the $\mathrm{B}_{2} \mathrm{O}_{6}$ framework and leads to an expansion of the lattice. This could explain the increased lattice parameters observed for the as-synthesized defect pyrochlore powders. Consequently, the removal of water molecules upon dehydration would then lead to a contraction of the lattice and then expand again when rehydrated, as observed in the in situ hot stage XRD experiments. This ready reversibility supports the proposal that physisorbed (e.g., hydrogen-bonded water molecules) rather than chemisorbed (e.g., hydroxyl groups) species are involved in the expansion and contraction of the lattice. The ability of physisorbed water to cause structural changes at room temperature has also been observed for other molecular sieve materials. ${ }^{31,32}$

\section{CONCLUSIONS}

Potassium tantalate powders were synthesized by the hydrothermal method at 100 to $200{ }^{\circ} \mathrm{C}$ in highly alkaline (4 to $15 \mathrm{M}$ ), aqueous $\mathrm{KOH}$ solutions for periods up to $48 \mathrm{~h}$. A defect pyrochlore, with the approximate formula, $\mathrm{K} \square \mathrm{Ta}_{2} \mathrm{O}_{5}(\mathrm{OH}) \square \cdot n \mathrm{H}_{2} \mathrm{O}(n \approx 1.4)$, was the stable composition at $4 \mathrm{M} \mathrm{KOH}$. At higher $\mathrm{OH}^{-}$concentration, the pyrochlore was only an intermediate phase; the pyrochlore reacted further with $\mathrm{KOH}$ to form a defect perovskite phase. At $15 \mathrm{M} \mathrm{KOH}$, no intermediate pyrochlore was formed and a defect perovskite phase, $\mathrm{K}_{0.85} \mathrm{Ta}_{0.92} \mathrm{O}_{2.43}(\mathrm{OH})_{0.57} \cdot 0.15 \mathrm{H}_{2} \mathrm{O}$, was the stable phase. Both phases contained $\mathrm{OH}^{-}$ions on oxygen sites and water molecules on vacant potassium and/or oxygen sites. The water molecules easily diffuse to the surface at temperatures $<350{ }^{\circ} \mathrm{C}$; for the pyrochlore, the water re-adsorbs from the atmosphere after cooling.

\section{ACKNOWLEDGMENTS}

This work was supported by the Materials Research Laboratory program of the National Science Foundation under Award No. DMR00-80034. G.K.L. Goh acknowledges the Institute of Materials Research and Engineering 
(Singapore) for the provision of a research scholarship. Dr. Sonjong Hwang of the California Institute of Technology kindly collected the NMR data.

\section{REFERENCES}

1. O.G. Vendik, E.K. Hollmann, A.B. Kozyrev, and A.M. Prudan, J. Superconductivity 12, 325 (1999).

2. H.M. Christen, L.A. Boatner, J.D. Budai, M.F. Chisholm, L.A. Gea, P.J. Marrero, and D.P. Norton, Appl. Phys. Lett. 68, 1488 (1996).

3. G.K.L. Goh, C.G. Levi, and F.F. Lange, J. Mater. Res. (in press).

4. A.T. Chien, J.S. Speck, F.F. Lange, A.C. Daykin, and C.G. Levi, J. Mater. Res. 10, 1784 (1995).

5. A.T. Chien, J.S. Speck, and F.F. Lange, J. Mater. Res. 12, 1176 (1997).

6. A. Reisman, F. Holtzberg, M. Berkenblit, and M. Berry, J. Am. Chem. Soc. 78, 4514 (1956)

7. S. Hirano, T. Yogo, K. Kikuta, T. Morishita, and Y. Ito, J. Am. Ceram. Soc. 75, 1701 (1992).

8. N. Duan, Z-R. Tian, W.S. Willis, S.L. Suib, J.M. Newsam, and S.M. Levine, Inorg. Chem. 37, 4697 (1998).

9. Powder Diffraction Files, Card No. 35-1464 (Joint Committee on Powder Diffraction Standards, Swarthmore, PA, 1992).

10. Powder Diffraction Files, Card No. 38-1470 (Joint Committee on Powder Diffraction Standards, Swarthmore, PA, 1992).

11. E. Brunner, H.G. Karge, and H. Pfeifer, Z. Phys. Chem. 176, 173 (1992).

12. S.Q. Fu, W-K. Lee, A.S. Nowick, L.A. Boatner, and M.M. Abraham, J. Solid State Chem. 83, 221 (1989).

13. A.T. Chien, X. Xu, J.H. Kim, J.S. Speck, and F.F. Lange, J. Mater. Res. 14, 3330 (1999).
14. D. Hennings and S. Schreinemacher, J. Eur. Ceram. Soc. 9, 41 (1992).

15. S. Wada, T. Suzuki, and T. Noma, J. Ceram. Soc. Jpn. 104, 383 (1996).

16. E-W. Shi, C-T. Xia, W-Z. Zhong, B-G. Wang, and C-D. Feng, J. Am. Ceram. Soc. 80, 1567 (1997).

17. M.T. Weller and P.G. Dickens, J. Solid State Chem. 58, 164 (1985).

18. S. Wada, T. Suzuki, and T. Noma, Jpn. J. Appl. Phys. 34, 5368 (1995).

19. R. Waser, Z. Naturforsch. 42a, 1357 (1987).

20. K.D. Kreuer, St. Adams, W. Münch, A. Fuchs, U. Klock, and J. Maier, Solid State Ionics 145, 295 (2001).

21. A-J. Li and R. Nussinov, Prot. 32, 111 (1998).

22. R.D. Shannon and C.T. Prewitt, Acta Crystall. B25, 925 (1969).

23. A.W. Sleight, Inorg. Chem. 7, 1704 (1968).

24. M.A. Subramanian, G. Aravanudan, and G.V. Subba Rao, Prog. Solid State Chem. 15, 55 (1983).

25. J. Pannetier, J. Phys. Chem. Solids 34, 583 (1973).

26. J.B. Goodenough, H.Y-P. Hong, and J.A. Kafalas, Mater. Res. Bull. 11, 203 (1976).

27. N. Kumada, N. Ozawa, N. Kinomura, and F. Muto, Mater. Res. Bull. 20, 583 (1985).

28. P.G. Dickens and M.T. Weller, Solid State Comm. 59, 569 (1986)

29. M.A. Butler and R.M. Biefeld, Phy. Rev. B 19, 5455 (1979).

30. K. Seff, in Recent Advances and New Horizons in Zeolite Science and Technology, Stud. Surf. Sci. Catal. 102, edited by H. Chon, S.I. Woo, and S-E. Park (1996), p. 267.

31. N.J. Tapp, N.B. Milestone, M.E. Bowden, and R.H. Meinhold, Zeolites 10, 105 (1990).

32. T.M. Nenoff, J.B. Parise, G.A. Jones, L.G. Galya, D.R. Corbin, and G.D. Stucky, J. Phys. Chem. 100, 14256 (1996). 